\title{
Gastrointestinal Stromal Tumours
}

\author{
Oguzhan Sunamak ${ }^{1}$, Mehmet Onur Gul ${ }^{2}$, Ismail Ege Subasi ${ }^{1}$, Turgut Donmez ${ }^{3}$ and Selvinaz Ozkara ${ }^{4}$ \\ ${ }^{1}$ Department of General Surgery, Haydarpasa Numune Training and Research Hospital, Istanbul, Turkey \\ ${ }^{2}$ Department of Surgical Oncology, Cukurova University, Adana, Turkey \\ ${ }^{3}$ Department of General Surgery, Bakirkoy Dr Sadi Konuk Training and Research Hospital, Istanbul, Turkey \\ ${ }^{4}$ Department of Pathology, Haydarpasa Numune Training and Research Hospital, Istanbul, Turkey
}

\begin{abstract}
Objective: To analyse the gastrointestinal stromal tumours (GIST) patients' inter-demographics, histological type and association with secondary tumours.

Study Design: A case series.

Place and Duration of the Study: Department of General Surgery, Haydarpasa Numune Training and Research Hospital, Istanbul, Turkey, between January 2010 and December 2018.

Methodology: Fifty-eight patients diagnosed with GIST and operated at the study place were analysed retrospectively. The demographics, symptoms, diagnosis, treatment, tumour location, histopathology, risk classification, and prognosis were recorded.

Results: The mean age was $60.62 \pm 10.63$ (37-83) years and the male to female ratio was $1: 1$. The most common symptom was abdominal pain (51.7\%). Tumour site was the stomach in the majority (86.2\%), followed by the small intestine and colon. One patient also had a secondary malignancy. The most common histologic type was spindle cell, followed by mixed cell type. C-kit (CD117) and CD34 mutations were positive in $87.9 \%$ and $75.9 \%$ of the cases. One patient had liver metastasis on diagnosis and another had peritoneal implants per-operatively, who died after 36 months due to midgut volvulus. The mean followup period was $32.03 \pm 13.67$ months. Two patients developed liver metastasis in the early postoperative period.

Conclusion: Surgical resection and imatinib treatment have been provided with good prognosis. The most common histology is spindle cell type. GISTs might be associated with other cancers which should be searched and analysed.
\end{abstract}

Key Words: Gastrointestinal stromal tumour, Secondary malignancy, Treatment, Prognosis.

How to cite this article: Sunamak O, Gul MO, Subasi IE, Donmez T, Ozkara S. Gastrointestinal Stromal Tumours. J Coll Physicians Surg Pak 2021; 31(09):1089-1093.

\section{INTRODUCTION}

Gastrointestinal stromal tumours (GISTs) are the most common mesenchymal tumours of the gastrointestinal tract. They are mostly seen in the stomach (60\%), followed by small intestines, colon, and rectum. Rarely, they can also be found in the omentum, mesentery, and retroperitoneum. ${ }^{3}$

These tumours take origin from interstitial Kajal cells which are pacemakers of intestinal peristalsis. They express KIT (CD117) (tyrosine kinase receptor growth factor); and DOG-1 surface protein mutations are frequent in these tumours. ${ }^{2,3}$ When KIT protein is absent, which is seen in $5 \%$ of them, platelet-derived growth factor receptor alpha (PDGFRA) mutation is common. ${ }^{3}$

Correspondence to: Dr. Mehmet Onur Gul, Department of Surgical Oncology, Cukurova University, Adana, Turkey E-mail: mehmetonurgul@hotmail.com

Received: September 28, 2020; Revised: December 17, 2020; Accepted: February 24, 2021

DOI: https://doi.org/10.29271/jcpsp.2021.09.1089
Patients with sporadic GIST may have an increased incidence of other cancer types; and patients with associated cancers have an increased mortality rate. ${ }^{4,5}$ However, the association between the GISTs and other cancer types needs further research.

The aim of this study was to present a single-centre experience of GIST diagnosis, in terms of distribution, association with other malignancies, treatment, and outcomes.

\section{METHODOLOGY}

Fifty-eight patients, who had the diagnosis of GIST and were operated between January 2010 and December 2018, were analysed retrospectively. The inclusion criteria were the diagnosis of GIST on histopathological analysis. Patient age, gender, clinical presentation, diagnosis, treatment, tumour site, secondary tumour association, histopathological analysis, risk classification, and prognosis were recorded. These parameters were also recorded for both gastric and non-gastric subgroups. There were no exclusion criteria for the study.

Diagnosis of the recurrence or the metastatic disease was made through clinical symptoms, imaging and endoscopic studies. 
Table I: Clinical demographics of GIST cases.

\begin{tabular}{|c|c|c|c|}
\hline \multirow[b]{2}{*}{ Demographics of the patients } & \multicolumn{3}{|l|}{ Patient numbers (\%) } \\
\hline & $\begin{array}{c}\text { Gastric vs. } \\
\mathrm{n}: 50\end{array}$ & $\begin{array}{c}\text { Non-gastric } \\
n: 8\end{array}$ & $\begin{array}{l}\text { Total } \\
\mathrm{n}: 58\end{array}$ \\
\hline $\begin{array}{l}\text { Age } \\
\leq 60 \\
>60\end{array}$ & $\begin{array}{l}20(40 \%) \\
30(60 \%)\end{array}$ & $\begin{array}{l}4(50 \%) \\
4(50 \%)\end{array}$ & $\begin{array}{l}24(41.4 \%) \\
34(58.6 \%)\end{array}$ \\
\hline $\begin{array}{l}\text { Gender } \\
\text { Male } \\
\text { Female }\end{array}$ & $\begin{array}{l}28(56 \%) \\
22(44 \%)\end{array}$ & $\begin{array}{l}1(12.5 \%) \\
7(87.5 \%)\end{array}$ & $\begin{array}{l}29(50 \%) \\
29(50 \%)\end{array}$ \\
\hline $\begin{array}{l}\text { Symptoms } \\
\text { Abdominal pain } \\
\text { Asymptomatic } \\
\text { Bleeding } \\
\text { Nausea and vomiting } \\
\text { Bloating and heartburn } \\
\text { lleus }\end{array}$ & $\begin{array}{c}25(50 \%) \\
16(32 \%) \\
6(12 \%) \\
2(4 \%) \\
1(2 \%) \\
0\end{array}$ & $\begin{array}{c}5(62.5 \%) \\
0 \\
1(12.5 \%) \\
1(12.5 \%) \\
0 \\
1(12.5 \%)\end{array}$ & $\begin{array}{c}30(51.7 \%) \\
16(27.6 \%) \\
7(12.1 \%) \\
3(5.2 \%) \\
1(1.7 \%) \\
1(1.7 \%)\end{array}$ \\
\hline $\begin{array}{l}\text { Diagnosis } \\
\text { Endoscopy } \\
\mathrm{CT}^{+} \\
\mathrm{MRI}^{++}\end{array}$ & $\begin{array}{c}24(48 \%) \\
23(46 \%) \\
3(6 \%)\end{array}$ & $\begin{array}{c}1(12.5 \%) \\
7(87.5 \%) \\
0\end{array}$ & $\begin{array}{c}25(43.1 \%) \\
30(51.7 \%) \\
3(5.2 \%)\end{array}$ \\
\hline
\end{tabular}

Table II: Histopathological findings.

\begin{tabular}{|c|c|c|c|}
\hline & \multicolumn{3}{|c|}{ Patient Number(\%) } \\
\hline & Gastric & Non-gastric & Total n:58 \\
\hline $\begin{array}{l}\text { Tumour size } \\
\leq 2 \mathrm{~cm} \\
2.1-5 \mathrm{~cm} \\
5.1-10 \mathrm{~cm} \\
>10 \mathrm{~cm}\end{array}$ & $\begin{array}{c}5(10 \%) \\
27(54 \%) \\
12(24 \%) \\
6(12 \%)\end{array}$ & $\begin{array}{l}3(37.5 \%) \\
1(12.5 \%) \\
2(25 \%) \\
2(25 \%)\end{array}$ & $\begin{array}{c}8(13.8 \%) \\
28(48.3 \%) \\
14(24.1 \%) \\
8(13.8 \%)\end{array}$ \\
\hline $\begin{array}{l}\text { Histological type } \\
\text { Spindle } \\
\text { Epitheliod } \\
\text { Mixed }\end{array}$ & $\begin{array}{c}31(62 \%) \\
6(12 \%) \\
13(26 \%)\end{array}$ & $\begin{array}{c}4(50 \%) \\
0 \\
4(50 \%)\end{array}$ & $\begin{array}{c}35(60.3 \%) \\
6(10.3 \%) \\
17(29.3 \%)\end{array}$ \\
\hline $\begin{array}{l}\text { Mitotic index } \\
\leq 5 \\
>5\end{array}$ & $\begin{array}{l}38(76 \%) \\
12(24 \%)\end{array}$ & $\begin{array}{l}5(62.5 \%) \\
3(37.5 \%)\end{array}$ & $\begin{array}{l}43(74.1 \%) \\
15(25.9 \%)\end{array}$ \\
\hline $\begin{array}{l}\text { Immunohistochemisty } \\
\text { CD117 (+++,++ positive) } \\
\text { CD34 (+++ positive) } \\
\text { SMA (+ positive) } \\
\text { S100 (+ positive) }\end{array}$ & $\begin{array}{c}45(90 \%) \\
40(80 \%) \\
1(2 \%) \\
3(6 \%)\end{array}$ & $\begin{array}{c}6(75 \%) \\
4(50 \%) \\
4(50 \%) \\
0\end{array}$ & $\begin{array}{c}51(87.9 \%) \\
44(75.9 \%) \\
5(8.6 \%) \\
3(5.2 \%) \\
\end{array}$ \\
\hline $\begin{array}{l}\text { NIH+ risk category } \\
\text { Very low risk } \\
\text { Low risk } \\
\text { Moderate risk } \\
\text { High risk }\end{array}$ & $\begin{array}{l}27(54 \%) \\
7(14 \%) \\
6(12 \%) \\
10(20 \%)\end{array}$ & $\begin{array}{c}3(37.5 \%) \\
0 \\
0 \\
5(62.5 \%)\end{array}$ & $\begin{array}{c}30(51.7 \%) \\
7(12.1 \%) \\
6(10.3 \%) \\
15(25.9 \%)\end{array}$ \\
\hline $\begin{array}{l}\text { Adjuvant treatment (imatinib) } \\
\text { Yes } \\
\text { No }\end{array}$ & $\begin{array}{l}16(32 \%) \\
34(68 \%)\end{array}$ & $\begin{array}{l}5(62.5 \%) \\
3(37.5 \%)\end{array}$ & $\begin{array}{l}21(36.2 \%) \\
37(63.8 \%)\end{array}$ \\
\hline
\end{tabular}

Statistical analysis was performed by using Statistical Package for the Social Sciences version 16 (SPSS Inc; Chicago, IL, USA). Descriptive data were given as mean and standard deviation (SD) for quantitative variables and in frequencies, and percent for qualitative variables.

\section{RESULTS}

The mean age was $60.62 \pm 10.63$ (37-83) years and the male to female ratio was $1: 1$. Sixty per cent of the gastric GIST patients were older than 60 years of age. Male dominance was prominent in gastric GIST patients and female dominance in patients with non-gastric GISTs (Table I).

The most common clinical symptom was abdominal pain 30 $(51.7 \%)$ in both gastric and non-gastric GIST cases. Asymptomatic patients were the second most common group in gastric GIST cases. Bleeding was another symptom. One patient was administered because of ileus and underwent an emergency operation. The diagnosis was made by using contrast CT imaging and endoscopy. While endoscopy and CT were the most commonly used diagnostic tools in gastric GISTs, CT was the most frequently used imaging method in 
non-gastric GIST cases (Table I).

Tumour was in the stomach in the majority of the patients $(86.2 \%)$ followed by the small intestine $(6.9 \%)$, colon $(3.4 \%)$ and one case $(1.7 \%)$ each in duodenum, appendix, caecum and intra-abdominal location. In one of the gastric GIST cases with nausea and vomiting, gastroduodenal intussusception was diagnosed. In one patient, GIST was in the form of an intraabdominal mass with unknown origin and accompanied by a tubal mass. Tumour resection and right salpingo-oophorectomy were performed and histopathology revealed high-risk GIST along with endometrial stromal sarcoma of salpinx and endometrial stromal borderline tumour of the ovary. Surgical procedures were wedge resection in $34(58.6 \%)$, subtotal gastrectomy in $17(29.3 \%)$, small intestine resection in $3(5.2 \%)$, hemicolectomy in $2(3.4 \%)$, subtotal colectomy in 1 (1.7\%), and intraabdominal tumour resection + salpingo-oophorectomy in $1(1.7 \%)$ of the cases, respectively.

Pathological and immunohistochemical analysis confirmed the GIST diagnosis in all patients. The mean tumour diameter was $6.06 \pm 4.26 \mathrm{~cm}$. The most common histological type was spindle cell $35(60.3 \%)$ followed by mixed cell 17 (29.3\%). C-kit (CD117) and CD34 mutations were positive in $51(87.9 \%)$ and $44(75.9 \%)$ of the patients, respectively. Ckit and CD34 mutations were positive in $45(90 \%)$ and 40 $(80 \%)$ of the gastric GIST cases and; in $6(75 \%)$ and $4(50 \%)$ of the non-gastric ones, respectively. Interestingly, SMA mutation was positive in $50 \%$ of the non-gastric GISTs, which was $2 \%$ in gastric GISTs (Table II).

National Institutes of Health (NIH) risk category for GIST were used to determine progression and recurrence risk and $30(51.7 \%)$ of the patients were in very low risk and 15 $(25.9 \%)$ of the patients in high risk. The majority of the gastric GIST cases consisted of the very low-risk group (27 patients; $54 \%$ of the gastric GIST cases); whereas, the majority of the non-GIST cases were in the high-risk group (5 patients; $62.5 \%$ of the non-gastric GIST cases). All high-risk patients were given imatinib treatment post-operatively (Table II).

On follow-up, CT imaging was used in all patients; it was taken annually in low risk and every three to the sixth month in high-risk patients. Endoscopy and colonoscopy were performed annually in patients with gastric and duodenal GIST; and colon GIST, respectively.

The mean follow-up period was $32.03 \pm 13.67$ months (2- 58). The disease-free survival was $31.33 \pm 13.76$ (2-58) months.

One patient with small intestinal GIST had liver metastasis on diagnosis and the other with intraabdominal GIST had peritoneal implants detected during surgery.

The patient who had an emergency operation died after 36 months, following another emergency operation due to midgut volvulus, which was not related to the disease (mortality rate: $1.7 \%)$.

Two patients with high-risk gastric GIST developed liver metastasis in the early postoperative period and detected on imaging studies on the 5th and 7 months, respectively) (3.4\%).

\section{DISCUSSION}

Despite being rare, the GISTs make 0.1 to $3 \%$ of all gastrointestinal tumours. ${ }^{6}$ They do not have gender predominance and are mostly seen after 50 years of age, though gender predominance might differ. ${ }^{2,6}$ The results of this study were also correlated with the literature. ${ }^{3}$

Having been smaller than $2 \mathrm{~cm}$ generally, they are mostly asymptomatic and detected incidentally, but, if symptomatic, abdominal pain and bleeding (hematemesis, melena, anaemia) are the most common clinical symptoms. ${ }^{3,7}$ Other common symptoms are nausea and vomiting, palpable mass, or ileus.

Abdominal pain was the most common symptom in the patients of this study. This might be due to the tumour size which was bigger than $2 \mathrm{~cm}$ in the majority of the study patients. However, literature shows the difference in the frequency of the symptoms; while the abdominal pain followed by gastrointestinal (GI) bleeding were the most common presenting symptoms in one study. Gl bleeding followed by abdominal mass were reported to be the most common symptoms in another one, although, most of the cases had a tumour size bigger than $2 \mathrm{~cm}$ in both of the studies. ${ }^{6,8,9}$

Ultrasound (US), magnetic resonance imaging (MRI), computed tomography (CT), PET-CT imaging; endoscopy and endoscopic-guided fine needle aspiration (FNA) or core biopsy are used for diagnosis., ${ }^{3,10}$ Recently, endoscopic ultrasound (EUS) has been a preferred method because it can differentiate the layers of the gastrointestinal system and allows needle or core biopsy. The main diagnostic methods were endoscopy and CT for gastric GISTs; and CT for non-gastric GISTs in this study; and FNA was performed in one patient with small intestine mesentery-originated GIST.

Surgical resection is the main curative treatment. ${ }^{11}$ It can be performed through open, laparoscopic, or combined laparoscopic-endoscopic surgery. ${ }^{3,12}$ Laparoscopic resection is the gold standard whenever possible. ${ }^{10}$ Tyrosine kinase receptor inhibitor imatinib mesylate is the suggested adjuvant treatment for inoperable cases with high-risk or metastatic cases. $^{10}$

As the GISTs are difficult to diagnose on only haematoxylin-eosin staining, some immunohistochemical methods have been developed. ${ }^{11}$ More than $95 \%$ t of the cases expresses CD 117 (KIT- KIT proto-oncogene receptor tyrosine kinase) and DOG-1 mutations; $80 \%$ expresses PDGFRA 
(platelet-derived growth factor receptor $\alpha$ ) and 70 to $80 \%$ expresses CD34. ${ }^{13}$ The tumours, which do not express neither KIT nor PDGRA mutations, are more aggressive and show poor prognosis. ${ }^{14}$ In this study, KIT and CD34 mutations were more prominent in gastric GISTs and less frequent in non-gastric ones. Their expression percents were near the lowest level that of the literature in total (Table II). Unfortunately, neither PDGFRA nor DOG-1 mutation analysis was not available, thus we had no results for them.

GISTs are usually well-demarcated masses and have mostly spindle ( $70 \%$ ), epitheloid (20\%) or mixed (10\%) cell types. ${ }^{13}$ However, in this study, the mixed cell type was more frequent than the epithelioid cell type (Table II).

National Health Institutes risk classification system was introduced for the estimation of prognosis and recurrence. ${ }^{15}$ In this study, this classification system was used and imatinib treatment was started for high-risk patients.

In literature, most of the recurrences were reported to be within the first five years after the surgery. Thus, a close follow-up to detect the relapses earlier for a better response to imatinib treatment and a better survival is important. ${ }^{16}$

The common metastatic sites for GISTs are the liver, the mesentery, and the omentum. Lung, lymph node, bone, pancreas and the colon are less common locations. ${ }^{9,17}$ The mean period for metastasis development after the diagnosis was reported to be 3.6 years. ${ }^{9}$

The liver was the most common metastatic site with three patients; one at the time of diagnosis and two during the follow-up period, in this study, followed by intraabdominal metastasis in one patient. Recurrence is commonly seen in high-risk patients. But, the introduction of the tyrosine kinase inhibitor, imatinib, improved the prognosis of GISTs even in metastatic patients. ${ }^{18,19}$ There was one case with synchronous liver metastasis in this study.

The incidence of secondary malignancies in association with GISTs was reported to be between 4.5 to $33 \% .{ }^{20}$ Hechtman et al. reported the second primary tumours detected before, during, and after the surgery for GISTs. They reported the secondary tumours in 50 out of 260 patients and stated that these tumours can be seen between 6 months and 6 years after the surgery. ${ }^{21}$

Most of these tumours are gastrointestinal cancers. Female genital tract tumours and sarcomas are much less. ${ }^{22}$ In our study, one case was very interesting because its histopathology revealed two other primary tumours associating Intraabdominal GIST, and both intraabdominal locations of GIST and association of sarcoma of salpinx with GIST were rarely seen entities. ${ }^{22}$ The factors on the survival of such patients are still debatable due to paucity in the number of cases. Our patient has been still alive without any recurrence at the end of the 30-months follow-up period.

\section{CONCLUSION}

While the commoner GISTs might be asymptomatic, less common non-gastric GISTs are symptomatic. Abdominal pain is the most common symptom. Surgical resection and imatinib treatment in high-risk patients have been provided with a good prognosis in these tumours. The spindle cell type is the most commonly seen histological type, followed by mixed and epithelioid cell types. While gastric GISTs may be associated with gastric cancer, non-gastric GISTs may be seen in association with gynaecological malignancies.

\section{ETHICAL APPROVAL:}

Ethical approval from the Ethics Committee of the Hospital was taken (No. 771/05/2019-11).

\section{PATIENTS' CONSENT:}

Informed consents from all patients were obtained.

\section{CONFLICT OF INTEREST:}

The authors declared no conflict of interest.

\section{AUTHORS' CONTRIBUTION:}

OS, MOG: Collected data, written manuscript, edited and critically reviewed the manuscript.

IES, TD, SO: Collected data and involved in written.

\section{REFERENCES}

1. Joensuu H, Hohenberger $P$, Corless CL. Gastrointestinal stromal tumour. Lancet 2013; 382(9896):973-83. doi: 10.1016/S0140-6736(13)60106-3.

2. Rubin BP, Heinrich MC, Corless CL. Gastrointestinal stromal tumour. Lancet 2007; 369(9574):1731-41. doi.org/10. 1016/S0140-6736(07)60780-6.

3. Sharma NR, Gopakumar H, Harrison S, Ehmke N, Zelt C. Gastric gastrointestinal stromal tumours (GIST): A case series and current state of the art in the workup and treatment of this rare disease. J Gastrointest Cancer 2017; 112:1486-87.

4. DeMatteo RP, Lewis J, Leung D, Mudan SS, Woodruff JM, Brennan MF. Two hundred gastrointestinal stromal tumours: Recurrence patterns and prognostic factors for survival. Ann Surg 2000; 231(1):51-8. doi: 10.1097/ 00000658200001000-00008.

5. Agaimy A, Wunsch PH, Sobin LH, Lasota J, Miettinen M. Occurrence of other malignancies in patients with gastrointestinal stromal tumours. Semin Diagn Pathol 2006; 23(2):120-9. doi: 10.1053/j.semdp.2006.09.004.

6. Alghamdi HM, Amr SS, Shawarby MA, Sheikh SS, Alsayyah AA, Alamri AM, et al. Gastrointestinal stromal tumours. A clinicopathological study. Saudi Med J 2019; 40(2):126-30. doi: 10.15537/smj.2019.2.23913.

7. Miettinen M, Lasota J. Gastrointestinal stromal tumours: Review on morphology, molecular pathology, prognosis, and differential diagnosis. Arch Pathol Lab Med 2006; 130(10): 1466-78. doi: 10.5858/2006-130-1466-GSTROM.

8. Ravikumar G, Kalegowda IY, Ananthamurthy A. Clinicopathologic spectrum of gastro intestinal stromal tumours - experi- 
ence at a tertiary care center. Indian J Cancer 2011; 48(4):466-70. doi: 10.4103/0019-509X. 92281.

9. Aghdassi A, Christoph A, Dombrowski F, Döring P, Barth C, Christoph J, et al. Gastrointestinal stromal tumours: Clinical symptoms, location, metastasis formation, and associated malignancies in a single center retrospective study. Dig Dis 2018; 36(5):337-45. doi: 10.1159/000489556.

10. Parab TM, DeRogatis MJ, Boaz AM, Grasso SA, Issack PS, Duarte DA, et al. Gastrointestinal stromal tumours: A comprehensive review. J Gastrointest Oncol 2019; 10(1):144-54. doi: 10.21037/jgo.2018.08.20.

11. Akahoshi K, Oya M, Koga T, Shiratsuchi Y. Current clinical management of gastrointestinal stromal tumor. World J Gastroenterol 2018; 24(26):2806-17. doi: 10.3748/wjg. 24.i26. 2806

12. Florin CM, Bogdan F, Cristian L, Maria TA, Mihai D, Viorel S. Surgical treatment of gastric GIST: Feasibility of laparoscopic resection and postoperative outcome. J Coll Physicians Surg Pak 2020; 30(5):519-22. doi: 10.29271/ jcpsp. 2020.05.519.

13. Schaefer IM, Mariño-Enríquez A, Fletcher JA. What is new in gastrointestinal stromal tumor? Adv Anat Pathol 2017; 24(5):259-67. doi: 10.1097/PAP.0000000000000158.

14. Liu X, Chu KM. Molecular biomarkers for prognosis of gastrointestinal stromal tumor. Clin Transl Oncol 2019; 21(2):145-51. doi: 10.1007/s12094-018-1914-4.

15. Fletcher CD, Berman JJ, Corless C, Gorstein F, Lasota J, Longley $\mathrm{BJ}$, et al. Diagnosis of gastrointestinal stromal tumours: A consensus approach. Hum Pathol 2002; 33(5):459-65. doi: 10.1053/hupa.2002.123545.
16. D’Ambrosio L, Palesandro E, Boccone P, Tolomeo F, Miano S, Galizia D, et al. Impact of a risk-based follow-up in patients affected by gastrointestinal stromal tumour. European J Cancer 2017; 78:122-32. doi: 10.1016/j.ejca. 2017.03.025.

17. Patnaik S, Jyotsnarani Y, Rammurti S. Radiological features of metastatic gastrointestinal stromal tumours. J Clin Imaging Sci 2012; 2:43. doi: 10.4103/2156-7514.99177

18. Beham AW, Schaefer IM, Schuler P, Cameron S, Ghadimi BM. Gastrointestinal stromal tumours. Int J Colorectal Dis 2012; 27:689-700.

19. Valsangkar N, Sehdev A, Misra S, Zimmers TA, O'Neil BH, Koniaris LG. Current management of gastrointestinal stromal tumours: Surgery, current biomarkers, mutations, and therapy. Surgery 2015; 158(5):1149-64. doi: 10.1016/j.surg.2015.06.027.

20. Pandurengan RK, Dumont AG, Araujo DM, Ludwig JA, Ravi V, Patel S, et al. Survival of patients with multiple primary malignancies: A study of 783 patients with gastrointestinal stromal tumour. Ann Oncol 2010; 21(10):2107-11. doi: 10.1093/annonc/mdq078.

21. Hechtman JF, DeMatteo R, Nafa K, Chi P, Arcila ME, Dogan S, et al. Additional primary malignancies in patients with gastrointestinal stromal tumour (GIST): A clinicopathologic study of 260 patients with molecular analysis and review of the literature. Ann Surg Oncol 2015; 22(8):2633-9. doi: 10.1245/s10434-014-4332-z.

22. Giuliani J, Bonetti A. The occurrence of gastrointestinal stromal tumours and second malignancies. J Gastrointest Cancer 2015; 46(4):408-12. doi: 10.1007/s12029-0159759-3. 